\title{
Dietary supplement of conjugated linoleic acids or polyunsaturated fatty acids suppressed the mobilization of body fat reserves in dairy cows at early lactation through different pathways
}

\author{
Nanbing Qin, ${ }^{*}$ Ali-Reza Bayat, $†$ Erminio Trevisi,‡ Andrea Minuti,‡ Piia Kairenius, $†$ Sirja Viitala, $\dagger$ \\ Mervi Mutikainen, $\dagger$ Heidi Leskinen, $\dagger$ Kari Elo, ${ }^{*}$ Tuomo Kokkonen, ${ }^{*}$ and Johanna Vilkki ${ }^{1}$ \\ *Department of Agricultural Sciences, PO Box 28, FI-00014 University of Helsinki, Finland \\ †Production Systems, Natural Resources Institute Finland (Luke), 31600 Jokioinen, Finland \\ fDepartment of Animal Sciences, Food and Nutrition, Faculty of Agriculture, Food and Environmental Science, \\ Università Cattolica del Sacro Cuore, 20123 Milan, Italy
}

\begin{abstract}
To investigate the metabolic changes in the adipose tissue (AT) of dairy cows under milk fat depression (MFD), 30 cows were randomly allocated to a control diet, a conjugated linoleic acid (CLA)-supplemented diet, or a high-starch diet supplemented with a mixture of sunflower and fish oil (2:1; as HSO diet) from 1 to $112 \mathrm{~d}$ in milk. Performance of animals, milk yield, milk composition, energy balance, and blood metabolites were measured during lactation. Quantitative PCR analyses were conducted on the AT samples collected at wk 3 and 15 of lactation. The CLA and HSO diets considerably depressed milk fat yield and milk fat content at both wk 3 and 15 in the absence of significant changes in milk protein and lactose contents. In addition, the HSO diet lowered milk yield at wk 15 and decreased dry matter intake of cows from wk 3 to 15. Compared with the control, both CLA and HSO groups showed reduced body weight loss, improved energy balance, and decreased plasma concentrations of nonesterified fatty acids and $\beta$-hydroxybutyrate at early lactation. The gene expression analyses reflected suppressed lipolysis in AT of the CLA and HSO groups compared with the control at wk 3, as suggested by the downregulation of hormone-sensitive lipase and fatty acid binding protein 4 and the upregulation of perilipin 2. In addition, the HSO diet promoted lipogenesis in AT at wk 15 through the upregulation of 1-acylglycerol-3-phosphate O-acyltransferase 2, mitochondrial glycerol-3-phosphate acyltransferase, perilipin 2, and peroxisome proliferator-activated receptor $\gamma$. The CLA diet likely regulated insulin sensitivity in
\end{abstract}

Received December 15, 2017.

Accepted May 8, 2018.

${ }^{1}$ Corresponding author: johanna.vilkki@luke.fi
AT as it upregulated the transcription of various genes involved in insulin signaling, inflammatory responses, and ceramide metabolism, including protein kinase B2, nuclear factor $\kappa \mathrm{B} 1$, toll-like receptor 4 , caveolin 1 , serine palmitoyltransferase long chain base subunit 1, and $\mathrm{N}$-acylsphingosine amidohydrolase 1 . In contrast, the HSO diet resulted in little or no change in the pathways relevant to insulin sensitivity. In conclusion, the CLA and HSO diets induced a shift in energy partitioning toward AT instead of mammary gland during lactation through the regulation of different pathways.

Key words: milk fat depression, lipolysis, insulin resistance, gene expression, ceramide

\section{INTRODUCTION}

High-producing dairy cows undergo negative energy balance (NEB) during the early stage of lactation due to insufficient DMI and the increasing nutrient requirement for lactation (Drackley et al., 2005). Adaptation to NEB may increase the risk of metabolic disorders, resulting from excessive mobilization of nutrients from body reserves (Ingvartsen, 2006). The NEB at early lactation can be attenuated by milk fat depression (MFD), as fat serves as the major energy component in milk (Moore et al., 2004). The MFD can be induced by dietary managements, for instance, by increasing the dietary concentrate/forage ratio, by increasing dietary starch level, or by dietary PUFA supplement (Kalscheur et al., 1997; Shingfield et al., 2006; Piccioli-Cappelli et al., 2014). Dietary starch level varies with the grain composition and therefore can be increased, for instance, by replacing barley with wheat (Bernard et al., 2016). A feeding strategy combining high starch level and PUFA supplement was found to effectively depress milk fat content (Zened et al., 2012). These MFD diets modify the ruminal biohydrogenation and increase the production of trans fatty acids that inhibit mammary lipogenesis (Shingfield et al., 2010; Ventto et al., 2017). 
Of these trans fatty acids, trans-10,cis-12 CLA is the only isomer whose role in MFD has been clearly established (Baumgard et al., 2000). Cis-9,trans-11 CLA is another CLA isomer that is often used in mixture with trans-10,cis-12 CLA because industrial synthesis results in a 1:1 mix of both isomers. However, evidence has been found suggesting that cis-9,trans-11 CLA has no effect on milk fat synthesis (Baumgard et al., 2000). The mechanisms underlying the MFD induced by trans-10, cis-12 CLA include the coordinated reduction in the expression of various lipogenic genes in the mammary gland (Harvatine and Bauman, 2006; Gervais et al., 2009). In addition, trans-10,cis-12 CLA treatment and other milk fat depression diets also influence the metabolism in nonmammary tissues, for instance, increase the expression of lipogenic genes of the adipose tissue (AT) during mid lactation (Harvatine et al., 2009; Thering et al., 2009). The coordination of metabolic changes in different tissues results in nutrient partitioning toward nonmammary tissues, particularly AT (Shingfield et al., 2010). During the periparturient period, nutrient partitioning is partly regulated by naturally occurring maternal insulin resistance (IR), which induces increased lipolysis and decreased lipogenesis in AT and thus leads to the mobilization of body fat reserves (Rico et al., 2015; Selim et al., 2015). Human and rodent studies suggest that IR in AT is affected differently by CLA isomers. Trans-10, cis-12 CLA was reported to reduce triglyceride (TG) stores in adipocytes by increasing IR (Kennedy et al., 2009), whereas cis-9,trans-11 CLA was claimed to have antidiabetic effects (Moloney et al., 2007).

Insulin resistance is triggered by ceramide, a sphingolipid abundant in cell membrane that blocks phosphoinositide 3-kinase (PI3K) insulin signaling pathway in rodents (Chavez et al., 2003). Moreover, IR is associated with SFA-induced inflammatory signaling that promotes the synthesis of ceramides (Chavez and Summers, 2012). In dairy cows, the mechanisms underlying IR remain uncertain. However, evidence has suggested that IR is associated with increased plasma, hepatic, and AT ceramide concentrations (Qin et al., 2017; Rico et al., 2017) and with upregulated inflammatory responses at gene expression level (Vailati-Riboni et al., 2016).

In the present study, we aimed to induce MFD in dairy cows by either applying dietary rumen-protected CLA supplement or a high-starch diet with PUFA supplement and investigate the effects of these diets on the lipid metabolism in AT. We hypothesized that these diets promote lipogenesis and inhibit lipolysis in AT during early lactation through the regulation of IR and the IR-related inflammatory responses and ceramide metabolism pathways.

\section{MATERIALS AND METHODS}

\section{Animals, Experimental Design, and Diets}

The National Ethics Committee (ESAVI/ 4997/04.10.03/2012, Hämeenlinna, Finland) approved all experimental procedures in accordance with the guidelines established by the European Community Council Directives 86/609/EEC (European Council, 1986). Thirty multiparous Nordic Red dairy cows of $792 \pm 72 \mathrm{~kg}$ (mean $\pm \mathrm{SD}$ ) BW during the last $2 \mathrm{wk}$ before calving and $2.9 \pm 1.0$ (mean $\pm \mathrm{SD}$ ) parity were recruited from 28 d before expected calving until 112 d postpartum but received the experimental diets only after calving. Cows were assigned to the diet groups to be comparable according to parity, BCS, BW, and Nordic total merit (http://www.nordicebv.info/ntm-nordic -total-merit-2). Cows were housed in an experimental barn with a loose housing system, had free access to water and salt block, and were milked twice daily at 0700 and $1645 \mathrm{~h}$.

During the transition period, cows were offered a standard prepartum concentrate supplement (Supplemental Table S1; https://doi.org/10.3168/jds.2017 -14298). Treatments comprised a basal diet based on grass silage $(\mathbf{C O N})$, the same basal diet supplemented with CLA supplement (CLA diet/group), or a grass silage-based diet containing high-starch concentrate and supplemented with $40 \mathrm{~g} / \mathrm{kg}$ of DM of a mixture of sunflower oil (EBM Grupp AS, Tallinn, Estonia) and fish oil (BASF, Ludwigshafen, Germany) in a 2:1 ratio (wt/wt) to induce MFD (HSO; Table 1). The CLA and HSO diets were formulated to induce a decrease in milk fat content during the first $112 \mathrm{~d}$ of lactation. The forage was restrictively fermented grass silage prepared from primary growth of mixed timothy $(P h$ leum pratense) and meadow fescue (Festuca pratensis) swards, grown at Jokioinen $\left(60^{\circ} 49^{\prime} \mathrm{N}, 23^{\circ} 28^{\prime} \mathrm{E}\right)$ treated with a formic acid-based ensiling additive $(5 \mathrm{~L}$ per $\mathrm{t}$, AIV 2 Plus, Valio Ltd., Finland). The CLA supplement was given as rumen-protected lipid encapsulate $(780 \mathrm{~g}$ of fatty acids $/ \mathrm{kg}$ ), containing both cis-9,trans-11 and trans-10, cis-12 isomers. Both CLA isomers were present at $100 \mathrm{~g} / \mathrm{kg}$ of supplement (Lutrell Pure, BASF, Ludwigshafen, Germany). Higher doses of CLA were used in early lactation to overcome the lower sensitivity of the mammary gland to CLA (Moore et al., 2004). Supplementation levels were $150 \mathrm{~g} / \mathrm{d}$ during 1 to 14 DIM, $125 \mathrm{~g} / \mathrm{d}$ during 15 to $21 \mathrm{DIM}$, and $100 \mathrm{~g} / \mathrm{d}$ from 22 DIM to the end of study which resulted in providing $15.0,12.5$, and $10.0 \mathrm{~g}$ of each isomer per day.

The diets were offered as a TMR with a forage: concentrate ratio of 55:45 on DM basis and were formulated to be iso-nitrogenous. The CLA supplement was 
Table 1. Formulation and ingredient composition of experimental $\operatorname{diets}^{1}$

\begin{tabular}{lrr}
\hline Item & CON & HSO \\
\hline Feed ingredient (g/kg of DM) $^{2}$ & & \\
Grass silage $^{2}$ & 550 & 550 \\
Rolled barley & 210 & 69 \\
Ground wheat & 0 & 209 \\
Molassed sugar beet pulp & 55 & 0 \\
Barley feed & 55 & 0 \\
Solvent-extracted rapeseed meal & 115 & 115 \\
Urea & 0 & 2 \\
Mixture of UFA & \\
Vitamin and mineral premix & \\
Chemical composition (g/kg of DM unless stated) & 15 & 15 \\
DM (g/kg as fed) & 548 & 551 \\
OM & 925 & 930 \\
CP & 159 & 157 \\
NDF & 379 & 333 \\
Water-soluble carbohydrate & 43.8 & 37.1 \\
Starch & 164 & 202 \\
Gross energy (MJ/kg of DM) & 18.0 & 18.8 \\
\hline
\end{tabular}

${ }^{1} \mathrm{CON}=$ control diet; $\mathrm{HSO}=$ high-starch diet supplemented with sunflower and fish oil $(2: 1)$.

${ }^{2}$ Mean fermentation characteristics of experimental silage: $\mathrm{pH}, 3.98$ in $\mathrm{DM}(\mathrm{g} / \mathrm{kg})$ lactic acid, 56.4; acetic acid, 20.6; propionic acid, 0.49 butyric acid, 0.56 ; soluble $\mathrm{N}$ (g/kg of total $\mathrm{N}), 514$; ammonium $\mathrm{N}(\mathrm{g} /$ $\mathrm{kg}$ of total N), 39.1; gross energy (MJ/ $\mathrm{kg}$ of DM), 17.67.

${ }^{3}$ Containing sunflower and fish oils $(2: 1, \mathrm{wt} / \mathrm{wt})$.

${ }^{4}$ Declared as containing $(\mathrm{g} / \mathrm{kg}$ ) calcium (190), magnesium (60), sodium (135), zinc (2.19), manganese (0.45), copper $(0.40) ;(\mathrm{mg} / \mathrm{kg})$ iodine (55), cobalt (35), selenium (30), and DL-tocopheryl acetate (550); (IU/ $\mathrm{kg})$ retinyl acetate $(220,000)$ and cholecalciferol $(40,000)$; Onni, Melica Finland Ltd., Vaasa, Finland.

top dressed and administered in 2 equal proportions at 0630 and $1830 \mathrm{~h}$ on a daily basis. Oil supplements replaced concentrate ingredients in HSO diet. The TMR were fed as 4 meals at 0630, 1300, 1600, and $1830 \mathrm{~h}$. Experimental diets were offered ad libitum to result in $5 \%$ refusals and formulated to meet or exceed requirements for ME and MP (Natural Resources Institute Finland, 2015).

\section{Measurements and Chemical Analysis}

Measurements of energy balance (EB) were conducted over a 4-d period after $1 \mathrm{~d}$ acclimatization starting on average $14 \mathrm{~d}$ postpartum and were repeated at 28-d intervals (wk 3, 7, 11, and 15) using indirect open-circuit respiration chambers. Feed intake and the output of feces, urine, and milk were measured in respiration chambers or dedicated metabolic units during 4 d of each EB measurement period. In addition, gaseous exchanges for cows entering the respiration chambers were measured during this period. The energy metabolism of half of the cows was assessed using respiration chambers, whereas that of the rest of the cows was estimated based on the total fecal and urinary collection assuming the same partitioning of gross energy for methane production as their counterparts.

Daily feed intake and milk yield were measured daily, but only the data during EB measurement period were involved in statistical analysis. Body weight was measured before morning and afternoon feeding throughout the experiment. The BW recorded during 3 consecutive days before and after EB measurement periods were averaged before statistical analysis to minimize the daily variation. Silage and concentrate samples were collected on a weekly basis and stored frozen $\left(-20^{\circ} \mathrm{C}\right)$ until chemical analysis following the procedures described by Shingfield et al. (2002). Representative samples of the $\mathrm{CON}$ and HSO diets were collected for DM measurements. Representative feces and urine sub-samples (50 $\mathrm{g} / \mathrm{kg}$ ) were collected daily and stored at $4^{\circ} \mathrm{C}$. At the end of each EB measurement period, sub-samples of feces and urine were composited and submitted for gross energy, DM, and nitrogen measurements. In addition, fecal samples were analyzed for ash, NDF, and starch using the procedures described by Shingfield et al. (2002). Gross energy of feed, fecal, and urinary samples was determined by bomb calorimetry (1108 Oxygen bomb, Parr Instrument, Moline, IL). Samples of morning and afternoon milk were collected daily during EB measurements, preserved with Bronopol tablets (Valio Ltd., Helsinki, Finland), and stored at $4^{\circ} \mathrm{C}$ until the determination of fat, $\mathrm{CP}$, and lactose contents by infrared analysis (MilkoScan 133B, Foss Electric, Hillerød, Denmark). The somatic cell count of milk was recorded monthly for the first 5 mo of lactation (Fossomatic analyzer, Foss Electric, Hillerød, Denmark).

Blood samples were collected from a jugular vein into vacuum tubes containing sodium heparin or EDTA or into serum tubes at $1200 \mathrm{~h}$ on the last day of EB measurement period and at $0600 \mathrm{~h}$ on $1 \mathrm{~d}$ after each EB measurement period. Plasma and serum were recovered by centrifugation at $2,083 \times g$ for 15 min at $4^{\circ} \mathrm{C}$, frozen immediately at $-20^{\circ} \mathrm{C}$, composited across sampling times for each cow, and stored at $-80^{\circ} \mathrm{C}$. Commercial routine analyses of blood concentrations of IGF-1, somatotropin, and leptin were performed on EDTA plasma samples (Laboklin GmbH \& Co., Helsinki, Finland). Analysis of blood insulin concentration was performed on serum samples using the RIA kit (PI-12K, Millipore Oy, Espoo, Finland), following the protocol described by Salin et al. (2012). Metabolic biomarkers in blood including glucose, cholesterol, TG, BHB, nonesterified fatty acids (NEFA), total bilirubin, haptoglobin, and ceruloplasmin were analyzed from plasma samples using the methods described by Piccioli-Cappelli et al. (2014) and Calamari et al. (2016). 


\section{Collection of Adipose Samples, RNA Extraction, and cDNA Synthesis}

Subcutaneous AT samples were collected after morning milking on $2 \mathrm{~d}$ after the EB measurement period at wk 3 and 15. Biopsy samples were obtained from the subcutaneous fat in the ischiorectal fossa region, several centimeters caudally from the sacrotuberous ligament. Cows were sedated with xylazine $(0.05 \mathrm{mg} / \mathrm{kg}$ intravenously, Narcoxyl $20 \mathrm{mg} / \mathrm{mL}$, Intervet International B.V., Boxmeer, the Netherlands) and local anesthesia was induced with $100 \mathrm{mg}$ of lidocaine (Lidocaine 20 $\mathrm{mg} / \mathrm{mL}$, Orion Corporation, Espoo, Finland) injected subcutaneously. The biopsy site was shaved and cleaned using Betadine solution and ethanol. Approximately 2 $\mathrm{g}$ of tissue was obtained through a 1-cm skin incision using a Weil-Blakesley rongeur (Braun Medical Oy, Helsinki, Finland). No suturing was made nor antibiotics given. The samples were immediately immersed in RNA stabilization reagent (RNAlater, Qiagen, Hilden, Germany), stored at $4^{\circ} \mathrm{C}$ overnight, and stored at $-80^{\circ} \mathrm{C}$ until RNA extraction after removal from RNALater solution.

Total RNA was extracted from frozen AT samples using RNeasy Lipid Tissue Mini Kit (Qiagen) following the method described by Selim et al. (2014). The concentration of total RNA solutions was measured with a NanoDrop ND-1000 spectrophotometer (NanoDrop Technologies, Wilmington, DE) based on the absorbance of the solution at 260 and $280 \mathrm{~nm}$. The average $260 / 280$ absorbance ratio of total RNA samples was $1.81 \pm 0.13$ (mean \pm SD). Chip electrophoreses were performed on total RNA solutions with Agilent Bioanalyzer 2100 chip electrophoresis system using Agilent RNA 6000 Nano Kit following the manufacturer's protocol (Agilent Technologies, Santa Clara, CA). The quality of RNA solutions were evaluated based on RNA integrity numbers and electropherograms. All the total RNA samples had adequate quality for the further analyses and showed average RNA integrity number of $6.92 \pm 0.60$ (mean $\pm \mathrm{SD}$ ). The first-strand cDNA was synthesized from the total RNA solution with Roche cDNA First Strand Synthesis Kit (Roche Diagnostics, Mannheim, Germany), using the method described by Selim et al. (2014).

\section{Primer Design and Real-Time PCR}

Primers for 28 AT candidate genes were designed with online Primer3 Plus program (Whitehead Institute for Biomedical Research, Cambridge, MA; Rozen and Skaletsky, 2000; Supplemental Table S2, https://doi.org/ 10.3168/jds.2017-14298). The uniqueness of primer sequences was inspected with the BLAST search tool and the GenBank sequence database of National Center for Biotechnology Information. All oligonucleotides for real-time (RT) PCR were commercially synthesized and purified by reverse phase cartridge (Oligomer, Helsinki, Finland). The RT-PCR analyses were performed in triplicates for each gene in one sample with LightCycler 480 (Roche Diagnostics). Each reaction contained $2.5 \mu \mathrm{L}$ of $1: 8$ diluted cDNA solution, $5 \mu \mathrm{L}$ of Roche's $2 \times$ master mix, $0.5 \mu \mathrm{L}$ of each forward and reverse primer $(5 \mathrm{pmol} / \mu \mathrm{L})$, and $1.5 \mu \mathrm{L}$ of DNase/RNase-free water. The temperature program of RT-PCR included an initial denaturation at $95^{\circ} \mathrm{C}$ for 5 min and 45 amplification cycles at $95^{\circ} \mathrm{C}$ for $20 \mathrm{~s}$, at $60^{\circ} \mathrm{C}$ for $20 \mathrm{~s}$, and at $72^{\circ} \mathrm{C}$ for $20 \mathrm{~s}$. A melting curve analysis was executed at the end of the PCR program.

The raw data from Lightcycler 480 was normalized with LinRegPCR (Heart Failure Research Center, Amsterdam, the Netherlands; Ruijter et al., 2009). The software performed the baseline correction for each reaction and calculated amplification efficiency of each reaction through the determination of window-oflinearity and further linear regression analysis based on the window-of-linearity. The initial expression level (NO) and cycle threshold in each reaction was calculated using the mean efficiency (Supplemental Table S2; https://doi.org/10.3168/jds.2017-14298) and the corrected baseline. Eukaryotic translation initiation factor 3, subunit K (EIF3K), hippocalcin-like 1 (HPCAL1), and mitochondrial ribosomal protein L39 (MRPL39) were chosen as internal control genes in RT-PCR analyses based on previous publications (Saremi et al., 2014; Vahmani et al., 2014). Their stability was evaluated with Normfinder algorithm in $\mathrm{R}$ program based on the cycle threshold values obtained from RT-PCR involving all $90 \mathrm{cDNA}$ samples (Andersen et al., 2004). EIF3K, HPCAL1, and MRPL39 showed stability given by Normfinder of $0.104,0.123$, and 0.115 , respectively.

\section{Calculations and Statistical Analysis}

The chemical composition of TMR was calculated based on that of individual feed ingredients (Table 1). Energy intake and energy excretion in feces or urine were calculated by multiplying feed or excreta DM by their respective gross energy contents. The ECM was calculated based on the yields of fat, $\mathrm{CP}$, and lactose $\{\operatorname{ECM}(\mathrm{kg} / \mathrm{d})=$ milk $(\mathrm{kg} / \mathrm{d}) \times[38.3 \times$ fat $(\mathrm{g} / \mathrm{kg})+$ $24.2 \times$ protein $(\mathrm{g} / \mathrm{kg})+16.54 \times$ lactose $(\mathrm{g} / \mathrm{kg})+$ $20.7] / 3,140\}$. Methane energy was calculated using the conversion factor $55.24 \mathrm{~kJ} / \mathrm{g}$. The ME input of cows was calculated using the formula $\mathrm{ME}_{\text {input }}=$ gross energy - feces energy - urine energy - methane energy (all in $\mathrm{MJ} / \mathrm{d}$ ). The ME requirement of cows was calculated using the formula $\mathrm{ME}_{\text {req }}(\mathrm{MJ} / \mathrm{d})=\mathrm{BW}^{0.75}(\mathrm{~kg}) \times 0.515$ 
$+5.15 \times \mathrm{ECM}(\mathrm{kg} / \mathrm{d})$ (Natural Resources Institute Finland, 2015). The EB was calculated by subtracting $\mathrm{ME}_{\text {req }}$ from $\mathrm{ME}_{\text {input }}$.

All statistical analyses were performed in SAS (release 9.3, SAS Institute Inc., Cary, NC). The relative expression levels of candidate genes to internal control genes were calculated (i.e., the ratio of the $\mathrm{N} 0$ of one candidate gene to the geometric mean of the N0 of EIF3K, HPCAL1, and MRPL39). The relative expression levels were $\log _{2}$-transformed before statistical analysis. The analysis of other data was conducted on the original values. The box-and-whisker plots were composed for all variables, grouped by diet and time. The observations out of the whiskers range in plots were considered as outliers and were removed from the further analyses (Pupovac and Petrovecki, 2011). The normality of all the variables was tested with PROC UNIVARIATE on the residuals obtained from PROC MIXED using diet, time, and their interaction as fixed effects. Repeated-measures ANOVA was performed on all the variables except for $\mathrm{BW}$ and $\mathrm{EB}$, using PROC MIXED with Tukey test and covariance structure of compound symmetry (CS), in which diet, time, and their interaction were set as fixed effects and animal was set as within-subject effect. The analysis of BW from wk 3 to 15 was performed using PROC MIXED with Tukey's test and covariance structure of autoregressive covariance structure $\mathrm{AR}(1)$, in which diet, time, and their interaction were set as fixed effects, animal was set as within-subject effect, and BW at wk 1 was set as covariate. The analysis of EB from wk 3 to 15 was performed in a 3-way ANOVA, using PROC MIXED with Tukey's test and autoregressive covariance structure $\mathrm{AR}(1)$, in which diet, time, EB calculation method, and the interactions between EB calculation method, time, and diet were set as fixed effects, animal was set as within-subject effect. Nonsignificant interactions between time and EB calculation method were dropped from the final model. $P \leq 0.05$ was considered to be statistically significant, and $0.05<P<0.10$ was considered as a tendency toward significance.

\section{RESULTS}

\section{Milk Yield and Composition}

The CLA and HSO diets altered milk production and the contents of various milk components (Table 2 ). The milk yields were similar in all the 3 groups at wk 3, whereas an interaction between diet and time effects $(P<0.001)$ was observed, characterized by an increase in the CON and CLA groups and a decrease in the HSO group over time points. The different pat- terns over time resulted in lower milk yield in the HSO group compared with the CON $(P=0.004)$ and CLA $(P=0.003)$ groups at wk 15 . The milk fat content was effectively depressed $(P<0.001)$ in the CLA and HSO groups at wk 3 and 15 relative to the CON group. Moreover, the HSO group showed even lower $(P<$ 0.001) milk fat content in comparison with the CLA group. Milk fat yield showed a similar pattern between groups at wk $3(\mathrm{HSO}<\mathrm{CLA}<\mathrm{CON} ; P<0.05)$. However, the differences in milk fat yield between the CON and CLA groups disappeared at wk 15. In contrast, the HSO group continued to have lower $(P<0.001)$ milk fat yield compared with the CON and CLA group at wk 15. The HSO group showed lower protein content compared with the other 2 groups and higher lactose content compared with the CLA group at wk $3(P<$ $0.05)$. These differences diminished in the following period and all the groups displayed similar protein and lactose contents at wk 15 . However, the protein and lactose yields in the HSO group dropped considerably over time and were lower in the HSO group compared with the other 2 groups at wk $15(P<0.05)$. In addition, ECM was effectively depressed in the HSO group compared with the CON group at wk 3 and $15(P<$ 0.001). The SCC was not affected by the diets (data not shown).

\section{Intake, Energy Balance, and BW Change}

The HSO diet lowered DMI $(P \leq 0.008)$ of cows from wk 3 to 15 and ME intake $(P<0.001)$ from wk 7 to 15 compared with the CON and CLA groups (Figure 1). Cows in the CON group displayed marked BW loss from wk 3 to 7 (Figure 1). In contrast, the BW of the CLA and HSO groups slightly dropped from wk 3 to 7 , followed by increases from wk 7 to 15 , resulting in higher BW compared with the CON group at wk 7 to $15(P=0.02$ for interaction of treatment and time). The EB of the CON group was lower $(P=0.03)$ than that of the HSO group and was numerically lower than that of the CLA group at wk 3 (Figure 1). However, in the CON group the EB increased rapidly after wk 3 , reaching a higher level $(P=0.03)$ than that in HSO group at wk 11. The interaction between EB calculation method and diet effect was not significant $(P=$ 0.31 ), suggesting the lack of influence of EB calculation method on the significance of the dietary effects.

\section{Blood Metabolites, Hormones, and Biomarkers}

Interactions between diet and time effects were observed in blood concentrations of NEFA $(P<0.001)$ and $\operatorname{BHB}(P=0.05$; Table 3$)$. At wk 3 , we observed 
Table 2. Milk yield and milk components of lactating cows fed different milk fat depression diets based on grass silage

\begin{tabular}{|c|c|c|c|c|c|c|c|c|}
\hline Item & $\begin{array}{l}\text { Week of } \\
\text { lactation }\end{array}$ & \multicolumn{3}{|c|}{ Treatment $^{1}$} & SEM & \multicolumn{3}{|c|}{$P$-value } \\
\hline ECM $(\mathrm{kg} / \mathrm{d})$ & $\begin{array}{l}3 \\
15\end{array}$ & $\begin{array}{l}42.3^{\mathrm{a}} \\
41.5^{\mathrm{a}}\end{array}$ & $\begin{array}{l}39.1^{\mathrm{ab}} \\
40.3^{\mathrm{a}}\end{array}$ & $\begin{array}{l}35.1^{\mathrm{b}} \\
33.1^{\mathrm{b}}\end{array}$ & 1.42 & $<0.001$ & 0.45 & 0.20 \\
\hline Fat yield $(\mathrm{g} / \mathrm{d})$ & $\begin{array}{l}3 \\
15\end{array}$ & $\begin{array}{l}1,840^{\mathrm{a}} \\
1,698^{\mathrm{a}}\end{array}$ & $\begin{array}{l}1,564^{\mathrm{b}} \\
1,535^{\mathrm{a}}\end{array}$ & $\begin{array}{l}1,224^{\mathrm{c}} \\
1,168^{\mathrm{b}}\end{array}$ & 67.3 & $<0.001$ & 0.052 & 0.45 \\
\hline Lactose yield $(\mathrm{g} / \mathrm{d})$ & $\begin{array}{l}3 \\
15\end{array}$ & $\begin{array}{l}1,734 \\
1,882^{\mathrm{a}}\end{array}$ & $\begin{array}{l}1,735 \\
1,941^{\mathrm{a}}\end{array}$ & $\begin{array}{l}1,851 \\
1,703^{\mathrm{b}}\end{array}$ & 62.1 & 0.75 & 0.031 & $<0.001$ \\
\hline Fat content (\%) & $\begin{array}{l}3 \\
15\end{array}$ & $\begin{array}{l}4.79^{\mathrm{a}} \\
4.13^{\mathrm{a}}\end{array}$ & $\begin{array}{l}4.07^{\mathrm{b}} \\
3.56^{\mathrm{b}}\end{array}$ & $\begin{array}{l}3.06^{\mathrm{c}} \\
3.15^{\mathrm{c}}\end{array}$ & 0.116 & $<0.001$ & $<0.001$ & $<0.001$ \\
\hline Protein content (\%) & $\begin{array}{l}3 \\
15\end{array}$ & $\begin{array}{l}3.55^{\mathrm{a}} \\
3.34\end{array}$ & $\begin{array}{l}3.58^{\mathrm{a}} \\
3.32\end{array}$ & $\begin{array}{l}3.29^{\mathrm{b}} \\
3.39\end{array}$ & 0.052 & 0.16 & $<0.001$ & $<0.001$ \\
\hline
\end{tabular}

${ }^{\mathrm{a}-\mathrm{c}}$ Different superscripts indicate differences between the mean values in the same row $(P<0.05)$.

${ }^{1} \mathrm{CON}=$ control diet; CLA $=$ CLA-supplemented diet; HSO $=$ high-starch diet supplemented with sunflower and fish oil $(2: 1)$.

lower blood NEFA $(P<0.001)$ and BHB $(P=0.001)$ concentrations in the CLA and HSO groups compared with the CON group. From wk 3 to 15, the NEFA concentration dropped considerably in the $\mathrm{CON}$ group (diet $\times$ time, $P<0.001$ ), but kept stable in the CLA and HSO groups, eliminating the differences between groups at wk 15. Blood glucose, TG, and cholesterol concentrations increased $(P<0.001)$ over time in all 3 groups. In addition, we observed higher $(P<0.001)$ blood glucose concentrations in the CLA and HSO groups compared with the CON group at both time points. Serum insulin concentration was not affected by the treatments. Blood concentration of hormones IGF-1 $(P=0.004)$, leptin $(P=0.031)$, and insulin $(P<$ 0.001 ) increased over time from wk 3 to 15 . In addition, we observed higher $(P=0.01)$ leptin concentration in the HSO group compared with the CON group and higher somatotropin concentrations in the CLA $(P<$ $0.001)$ and HSO $(P=0.03)$ groups compared with the CON group at wk 3 . An interaction $(P=0.04)$ between diet and time effects was observed on somatotropin concentration as it increased in the CON group, decreased in the CLA group, and kept stable in the HSO group, which eliminated the differences between groups at wk 15.

The concentrations of positive acute phase proteins, haptoglobin and ceruloplasmin, decreased over time $(P$ $<0.001$ and $P=0.01$, respectively). The HSO group showed higher concentrations in comparison with the CON group in the whole period for both proteins $(P=$ 0.04 for haptoglobin and $P<0.001$ for ceruloplasmin). The CLA group showed similar haptoglobin concentra- tion in the whole period, whereas lower ceruloplasmin concentration $(P<0.001)$ at wk 3 compared with the CON group. Moreover, the CLA group had a lower $(P$ $<0.001$ ) concentration of ceruloplasmin at each time point compared with the HSO group. Bilirubin concentration showed a decrease $(P<0.001)$ over time in all groups and was lower in the CLA group at wk 3 compared with CON $(P=0.003)$ and HSO $(P<$ 0.001). At wk 15, the difference between the CLA and CON groups disappeared and these 2 groups showed lower $(P \leq 0.01)$ levels compared with the HSO group.

\section{Gene Expression in Adipose Tissue}

Among genes involved in lipid metabolism, 6 genes displayed altered expression levels over time (Figure 2 and Figure S1; https://doi.org/10.3168/jds.2017 -14298). We observed decreases or tendencies toward decrease in adipose triglyceride lipase $(A T G L ; P=$ $0.02)$, diacylglycerol O-acyltransferase 1 (DGAT1; $P$ $=0.09)$, hormone-sensitive lipase ( LIPE; $P=0.06)$, perilipin 1 ( $P L I N 1 ; P=0.002)$, and sterol regulatory element binding transcription factor 1 (SREBF1; $P$ $=0.02$ ) over time. Diacylglycerol O-acyltransferase 2 (DGAT2) was the only gene that tended to increase $(P=0.05)$ in expression from wk 3 to 15 . Diet effects were only observed on the expression level of 1-acylglycerol-3-phosphate O-acyltransferase 2 (AGPAT2; P $=0.004)$ and perilipin $2(P L I N 2 ; P=0.005$; Figure 2 ). The expression of AGPAT2 was higher in the HSO group compared with the CLA group $(P=0.001)$ and CON group $(P=0.03)$ during the whole period. The 
expression of $P L I N 2$ was higher $(P \leq 0.004)$ in the CLA and HSO groups compared with the CON group during the whole period. The comparison within time points showed that the expression of adipocyte fatty acid binding protein $4(F A B P 4)$ tended to be lower $(P$ $=0.09)$ in the CLA group compared with the CON group at wk 3 , whereas its expression was similar in all the groups at wk 15 (Figure 2). Mitochondrial glycerol3-phosphate acyltransferase (GPAM) expression tended to be higher $(P=0.08)$ in the HSO group compared with the CLA group at wk 15. Compared with the CON, the CLA and HSO diets tended to decrease $(P \leq$ 0.07 ) the expression of $L I P E$ at wk 3 but not at wk 15 .
In addition, the expression of peroxisome proliferatoractivated receptor gamma $(P P A R G)$ in the $\mathrm{CON}$ group was higher $(P=0.04)$ compared with the CLA group and tended to be higher $(P=0.09)$ compared with the HSO group at wk 3. From wk 3 to $15, P P A R G$ expression decreased in the CON group whereas it increased in the CLA and HSO groups, characterized by the interaction $(P=0.020)$ between diet and time effects. As a consequence, the HSO tended $(P=0.07)$ to have higher PPARG expression compared with the CON group at wh 15 .

The expression of most candidate genes associated with insulin signaling, inflammatory responses, and
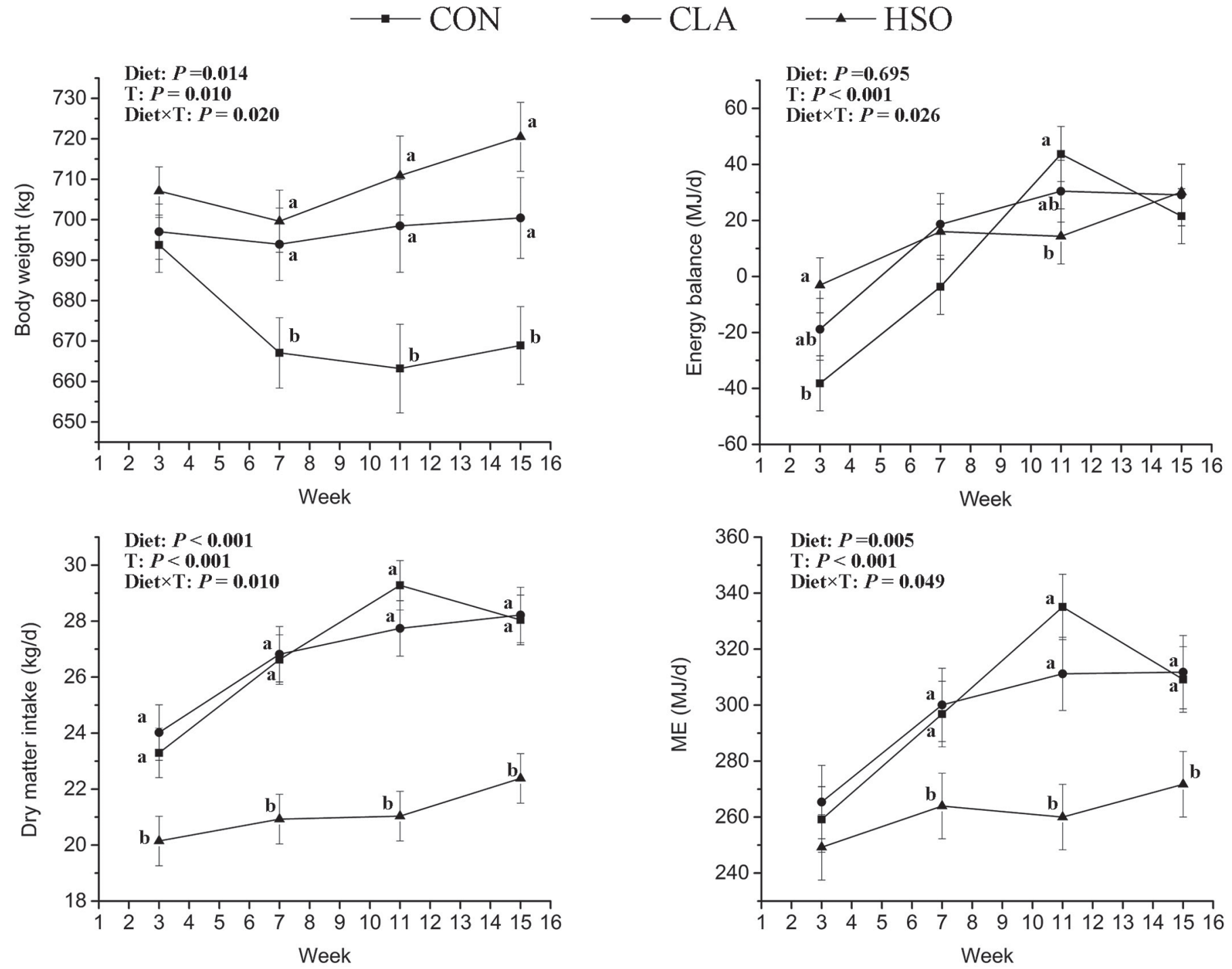

Figure 1. Body weight, energy balance, DMI, and ME intake of cows from wk 3 to 15 of lactation. The mean values in the graph are the LSM obtained from repeated measures ANOVA in SAS (release 9.3, SAS Institute Inc., Cary, NC). The error bars are the bootstrapped SE obtained from the same analysis. Different letters indicate the significant difference between groups at different time points. CON $=$ control diet; CLA $=$ CLA-supplemented diet; HSO = high-starch diet supplemented with sunflower and fish oil $(2: 1) ; \mathrm{T}=$ time. 
Table 3. Concentrations of blood metabolites of lactating cows fed different milk fat depression diets based on grass silage

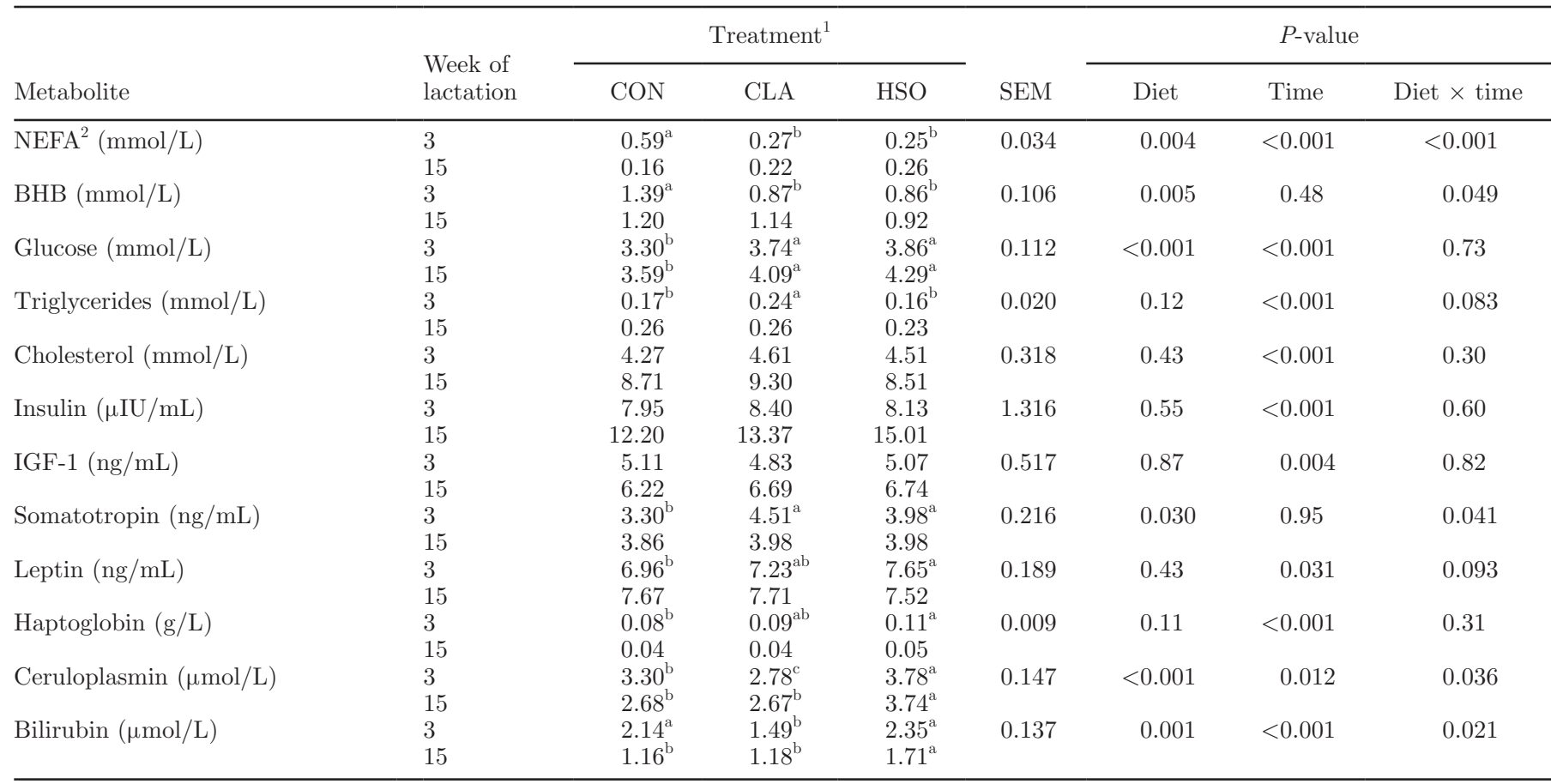

${ }^{\mathrm{a}-\mathrm{c}}$ Different superscripts indicate differences between the mean values of feeding groups in the same row $(P<0.05)$.

${ }^{1} \mathrm{CON}=$ control group; CLA $=$ group of cows in a CLA-supplemented diet; HSO = group of cows in a milk fat depression diet.

${ }^{2} \mathrm{NEFA}=$ nonesterified fatty acids.

sphingolipid metabolism displayed increases or tendencies toward increase in their expression over time (Figure 3 and Supplemental Figure S1, https://doi.org/10 $.3168 /$ jds.2017-14298). These included protein kinase $\mathrm{B} 1(A K T 1 ; P=0.001)$, protein kinase B2 $(A K T 2 ; P<$ $0.001), N$-acylsphingosine amidohydrolase 1 ( $A S A H 1 ; P$ $=0.098)$, caveolin 1 (CAV1; $P<0.001)$, insulin receptor substrate 1 (IRS1; $P<0.001$ ), nuclear factor $\kappa \mathrm{B} 1$ (NFKB1; $P=0.056$ ), sphingomyelin phosphodiesterase 1 (SMPD1; $P<0.001$ ), serine palmitoyltransferase long chain base subunit 1 (SPTLC1; P $<0.001$ ), serine palmitoyltransferase long chain base subunit 1 (SPTLC2; $P<0.001$ ), serine palmitoyltransferase small subunit A (SPTSSA; $P<0.001)$, and toll-like receptor 4 (TLR 4; $P=0.066)$. The CLA diet elevated the expression of AKT2 $(P \leq 0.002)$ and TLR4 $(P \leq 0.02)$ at wk 3 relative to the $\mathrm{CON}$ and $\mathrm{HSO}$ diets (Figure 3 ). The expression of $S P T L C 1$ tended to be raised $(P \leq 0.09)$ in the CLA group at wk 3 compared with the CON and HSO groups. In addition, the CLA group tended to have higher $(P \leq 0.09)$ expression of $A S A H 1, C A V 1$, and NFKB1 compared with the CON group at wk 3 . In contrast to the CLA diet, the HSO diet mainly showed its effects at wk 15. The expression of AKT2 in the HSO group was higher $(P=0.047)$ compared with the CLA group and tended to be higher $(P=0.052)$ com- pared with the CON group at wk 15. Similarly, SMPD1 expression was elevated $(P \leq 0.01)$ by the HSO diet at wk 15 compared with the CON and CLA diets.

\section{DISCUSSION}

\section{Milk Fat-Depressing Effect of Diets}

Both the CLA and HSO diets effectively induced the depression of milk fat content at both wk 3 and 15 . The HSO diet presented a stronger MFD effect compared with the CLA diet by inducing a more pronounced decrease in milk fat content and by significantly decreasing milk fat yield for longer period (until wk 15). Although not statistically significant, the drop of milk fat yield in the CLA group compared with the CON group at wk 15 was still numerically considerable $(>150$ $\mathrm{g} / \mathrm{d}$ ). Furthermore, the depression of milk fat was also reflected by the profiles of ECM in the CLA and HSO groups at wk 3 and 15. Previously, CLA isomers have been proven to depress milk fat content by inhibiting the expression of various enzymes for fat synthesis in the mammary gland (Baumgard et al., 2000; Bauman et al., 2011). Decrease in milk fat content has also been observed in dairy cows fed high-starch diets, PUFA supplement, or both (Shingfield et al., 2006; Pirondini 


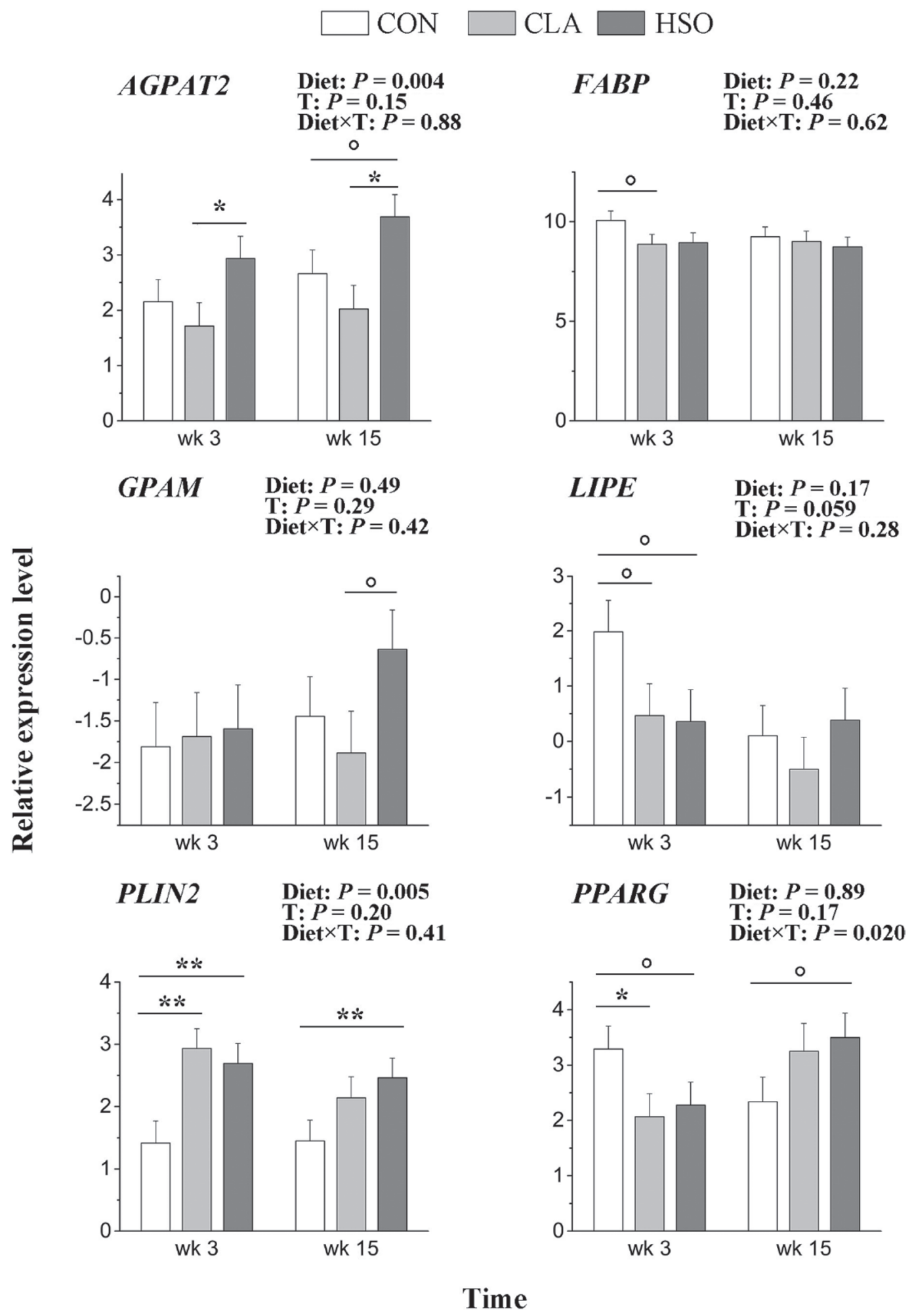

Figure 2. Expression of genes involved in lipid metabolism in adipose tissue. The mean values in the graph are the LSM of $\log _{2}$-transformed data obtained from repeated measures ANOVA in SAS (release 9.3, SAS Institute Inc., Cary, NC). The error bars are the bootstrapped SE of $\log _{2}$-transformed data obtained from the same analysis. Difference between 2 feeding groups within time points: ${ }^{\circ} P<0.10 ;{ }^{*} P<0.05 ; * * P<$ 0.01. $\mathrm{CON}=$ control diet; CLA $=$ CLA-supplemented diet; $\mathrm{HSO}=$ high-starch diet supplemented with sunflower and fish oil $(2: 1)$; $\mathrm{T}=$ time; AGPAT2 = 1-acylglycerol-3-phosphate O-acyltransferase 2; FABP4 = adipocyte fatty acid binding protein 4; GPAM= mitochondrial glycerol3-phosphate acyltransferase; $L I P E=$ hormone-sensitive lipase; PLIN2 $=$ perilipin 2; PPARG $=$ peroxisome proliferator-activated receptor gamma. 


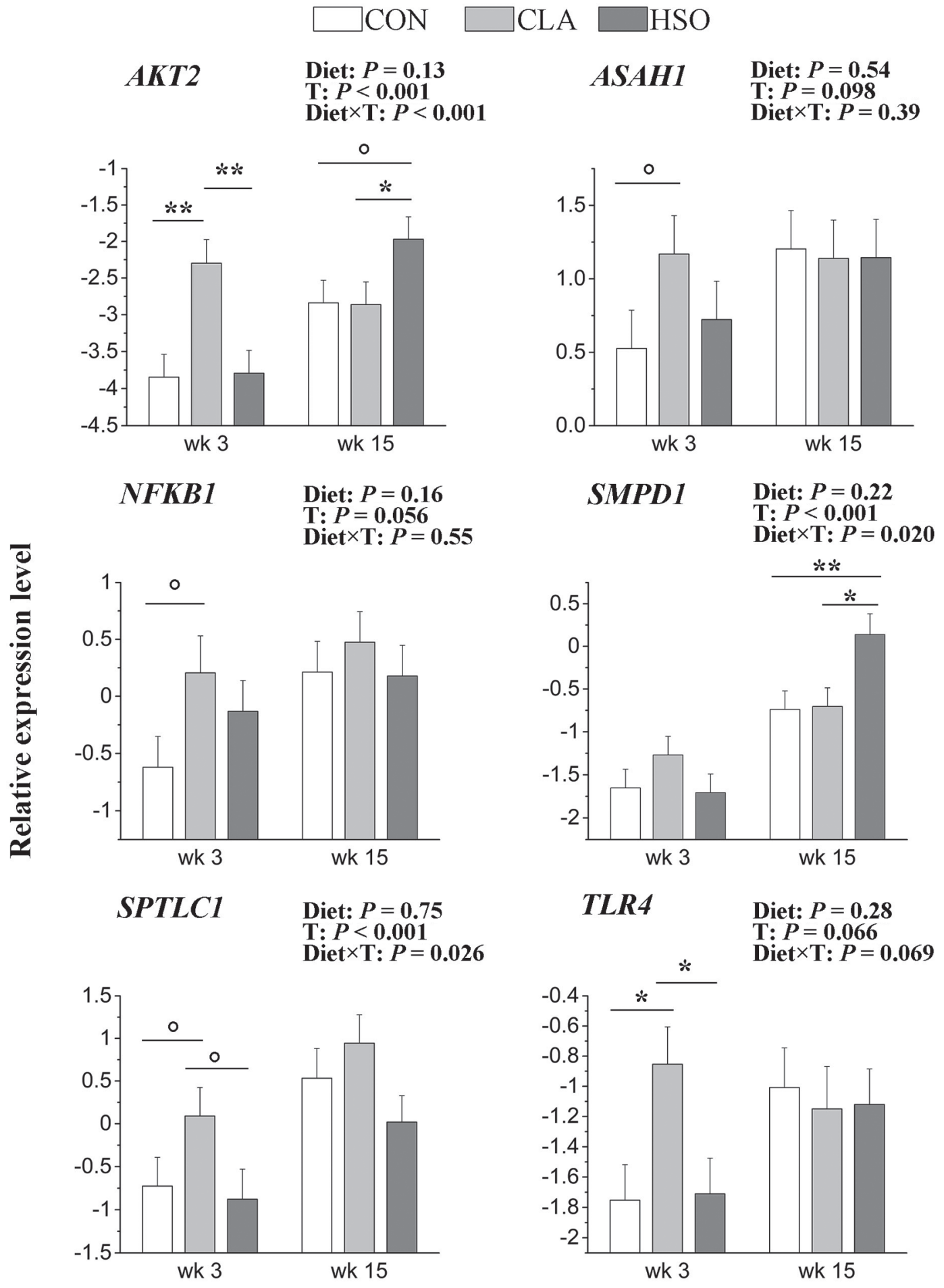

\section{Time}

Figure 3. Expression of genes involved in sphingolipid metabolism and insulin signaling. The mean values in the graph are the $\mathrm{LSM}_{\mathrm{S}}$ of $\log _{2^{-}}$ transformed data obtained from repeated measures ANOVA in SAS (release 9.3, SAS Institute Inc., Cary, NC). The error bars are the bootstrapped SE of $\log _{2}$-transformed data obtained from the same analysis. Difference between 2 feeding groups within time points: ${ }^{\circ} P<0.10 ; * P<$ 0.05; ${ }^{* *} P<0.01 ; \mathrm{CON}=$ control diet; $\mathrm{CLA}=\mathrm{CLA}$-supplemented diet; HSO = high-starch diet supplemented with sunflower and fish oil $(2: 1)$; $\mathrm{T}=$ time; $A K T 2=$ protein kinase B2; $A S A H 1=N$-acylsphingosine amidohydrolase $1 ; N F K B 1=$ nuclear factor $\kappa$ B1; SMPD1 $=$ sphingomyelin phosphodiesterase 1; SPTLC1 = serine palmitoyltransferase long chain base subunit 1; TLR4 = toll-like receptor 4 . 
et al., 2015). In addition, suppression of lipogenic genes in mammary gland was observed in cows fed plant and marine oil-derived long-chain PUFA (Ahnadi et al., 2002; Angulo et al., 2012). Moreover, replacing barley with wheat slightly in the current study increased the starch content and was previously observed to decrease milk fat content in dairy goats (Bernard et al., 2016), in line with the performance of cows in the HSO group. The lack of significant difference in milk fat yield between the CLA and CON groups at wk 15 resulted from the numerically higher milk yield in the CLA group. The mechanisms underlying the effect of CLA on milk yield is unclear. Several publications reported that milk yield was not affected by either dietary CLA supplement or abomasal infusion of CLA (Baumgard et al., 2000; Perfield et al., 2002). On the other hand, increases in milk yield were observed in cows fed CLAsupplemented diets (Shingfield et al., 2004; Galamb et al., 2017). Different from the CLA diet, the HSO diet decreased milk yield at wk 15, leading to decreased milk protein and lactose yields at wk 15 in the absence of differences in milk protein and lactose contents between groups. Correspondingly, reduced milk yield was observed in dairy goats fed high-starch diet versus low-starch diet (Bernard et al., 2016).

\section{Alterations in Animal Performance and Blood Metabolites During MFD}

Intakes of DM and $\mathrm{ME}$ were not influenced by the CLA diet, whereas they were remarkably decreased in the HSO group during lactation. Similar drops in DMI were observed when lactating cows were fed fish oil and sunflower oil (Shingfield et al., 2006; do Prado et al., 2015). The decreases in DMI under dietary oil supplements may have resulted from the negative effect of UFA on rumen function and the increase in flow of biohydrogenation intermediates at duodenum (Shingfield et al., 2006). Based on previous studies, the decreased DMI may partly explain the decrease in milk yield and milk fat yield in the HSO group. All the groups developed NEB at wk 3 and increases in EB in the following period. Improved EB were previously reported in lactating dairy cows fed mixture of cis-9,trans-11 and trans-10,cis-12 CLA at different stages of lactation (Odens et al., 2007; Schlegel et al., 2012). In contrast, contradictory results were reported on the EB of cows fed PUFA-rich oil due to the variation in DMI and milk production (Grummer and Carroll, 1991). In the present study, the numerically higher EB in the CLA group and the significantly higher EB in the HSO group compared with the CON group at wk 3 likely resulted from the reduction in milk fat synthesis. However, the decreased DMI in the HSO group may have slowed down the EB recovery to positive. In contrast, the EB of the CON group recovered to positive status at a faster rate compared with the other 2 groups from wk 3 to 11. Collectively, the CLA and HSO diets alleviated the NEB at early lactation. However, the improvements in EB by the CLA and HSO diets diminished when EB reached a positive level at wk 7 . The beneficial effects of the CLA and HSO diets on EB were also reflected by BW changes over time, as the CON group that had more serious NEB had also a greater BW loss over time compared with the CLA and HSO groups.

The adaptation to NEB during the periparturient period in dairy cows includes the mobilization of body reserves to the tissues in demand (Ingvartsen, 2006). The NEFA derived from lipolysis in AT serves as an important source for mammary fat synthesis and for energy production in the liver (Bauman and Griinari, 2003; Adewuyi et al., 2005). Incomplete hepatic oxidation of NEFA produces BHB (LeBlanc, 2010). Both plasma NEFA and BHB concentrations are used as indicators of lipid mobilization and EB in dairy cows (LeBlanc, 2010). The lower blood NEFA and BHB concentrations in the CLA and HSO groups at wk 3 indicated less lipid mobilization and further supported the improved EB in these groups compared with the CON group at wk 3 . The reduced lipid mobilization is likely associated with the depression of milk fat synthesis in the 2 groups. Our results are in line with previous studies in which plasma NEFA levels were decreased by dietary supplement of CLA isomers at early lactation (Odens et al., 2007; Hutchinson et al., 2011). Decreased NEFA and BHB concentrations were previously reported also in cows fed fish oil supplement in the first 2 wk of lactation (Ballou et al., 2009).

The MFD induced by the CLA and HSO diets were accompanied by increases in plasma glucose concentration at wk 3 and 15 . These results were consistent with previous results from cows fed CLA supplement in the first 7 wk of lactation (Odens et al., 2007; Hötger et al., 2013) and from those fed n-3 PUFA-rich fish oil and linseed (Ballou et al., 2009; Dirandeh et al., 2016). Odens et al. (2007) attributed the increased glucose concentration to decreased whole-body insulin sensitivity. Hötger et al. (2013) demonstrated that trans-10,cis-12 CLA reduced endogenous glucose production and at the same time reduced the glucose demand in the tissues, eventually leading to increased plasma glucose concentration. The increase in glucose concentrations in the CLA and HSO groups at wk 3 may be driven by the higher somatotropin concentrations in these 2 groups compared with the CON group, as somatotropin has been found to stimulate hepatic gluconeogenesis to supply the energy demand of the lactating mammary gland (Knapp et al., 1992). Plasma 
somatotropin level generally increases with aggravated NEB at early lactation (Bell, 1995). However, the reason for the increase in somatotropin concentration in the present study is uncertain as the CLA and HSO groups actually showed improved EB compared with the CON group at wk 3. The blood leptin concentration in dairy cows generally decreases at early lactation, facilitating the allocation of glucose and NEFA toward the mammary gland under NEB (Block et al., 2001). Therefore, higher plasma leptin concentration in the HSO group further supported the improved EB compared with the CON group. In addition, the increased plasma leptin concentration in the HSO group may explain the lower DM and ME intakes compared with the other 2 groups (Kokkonen et al., 2005).

The cows in all the groups showed an attenuation of the inflammatory condition moving away from parturition, as suggested by the reduction in the levels of inflammation indicators, haptoglobin, ceruloplasmin, and bilirubin (Trevisi et al., 2012; Bertoni and Trevisi, 2013). Considering the diet effect, the CLA group showed a less severe systemic inflammatory condition in comparison with the CON and HSO groups, particularly at wk 3 , as supported by the lower levels of ceruloplasmin, and bilirubin in the plasma, which was consistent with a previous finding (Trevisi et al., 2008). The profiles of these biomarkers suggested that the CLA diet may attenuate NEB and decrease the metabolic stress during the periparturient period (Trevisi et al., 2012). In contrast, the HSO group showed a slower decline in the inflammation status from wk 3 to 15 , as suggested by the higher levels of ceruloplasmin and bilirubin compared with the other 2 groups.

\section{Transcriptional Regulation of Lipid Metabolism in Adipose Tissue During MFD}

The decrease or the tendency toward decrease in the expression of LIPE and ATGL in AT over time suggested potential decreases in lipolysis from early to mid lactation in all of the groups, which may explain the declines in milk fat content at mid relative to early lactation. Expression of LIPE decreased in the CON and CLA groups, whereas it stayed stable in the HSO group, corresponding to the patterns of plasma NEFA level in these groups, which further indicated the role of $L I P E$ in the lipolysis in AT during lactation. Therefore, the tendencies toward downregulation of LIPE expression in the CLA and HSO groups at wk 3 suggested the downregulation of lipolysis in AT at the transcription level compared with the CON group at early lactation. The potential downregulation of lipolysis was further supported by the lower expression of FABP4 in the CLA and HSO groups compared with the CON group, as FABP4 facilitates the transport of intracellular fatty acids toward cellular membrane through its interaction with LIPE (Furuhashi and Hotamisligil, 2008). Urrutia and Harvatine (2017) observed similar repression of lipolytic genes $L I P E$ and FABP 4 in AT when lactating dairy cows were treated with abomasal infusion of trans-10,cis-12 CLA. In addition, reduced lipolysis in AT was observed in periparturient goats fed PUFArich oil (Invernizzi et al., 2016). Collectively with the profiles of NEFA, BHB, and EB, these alterations in gene expression may further support the decreased mobilization of body fat reserves in the CLA and HSO groups at early lactation in comparison with the CON group. Previously, a comparative experiment suggested that trans-10,cis-12 and cis-9,trans-11 CLA supplement decreased body fat mobilization by $40 \%$ from 1 to 42 DIM (von Soosten et al., 2012). As a consequence of decreased fat mobilization, an increasing amount of fat may be deposited in subcutaneous AT as lipid droplets, deduced from the upregulation of PLIN2 in the CLA and HSO groups compared with the CON group, encoding a surface component of lipid droplets.

Shingfield et al. (2010) suggested that MFD leads to a shift of energy partitioning toward AT instead of lactating mammary gland. In an earlier study, MFD induced by abomasal infusion of trans-10, cis-12 CLA at mid lactation was accompanied by increased lipogenesis in $\mathrm{AT}$ in addition to decreased lipolysis, characterized by the upregulation of various lipogenic genes, including fatty acid synthase $(F A S N)$, lipoprotein lipase $(L P L)$, stearoyl-CoA desaturase $(S C D)$, sterol regulatory element binding transcription factor 1 (SREBP1), thyroid hormone responsive (THRSP), and PPARG (Harvatine et al., 2009). We observed no upregulation of lipogenic genes but downregulation of PPARG in the CLA and HSO groups compared with the CON group at wk 3. At wk 15, higher expression of AGPAT2 and GPAM suggested potentially greater TG synthesis in the HSO group compared with the CON group. The upregulation of these genes in the HSO group was likely mediated by PPARG as the HSO group tended to have higher PPARG expression at the same time point. Furthermore, increased lipogenesis in the HSO group compared with the CON group at wk 15 may have resulted in increased deposition of lipid droplets as suggested by the higher expression of PLIN2. Corresponding results were previously observed in dairy cows fed PUFA-rich oil, as the upregulation of various lipogenic genes in AT, including PLIN2, lipin 1 (LPIN1), $S C D, L P L, T H R S P$, and PPARG (Thering et al., 2009; Schmitt et al., 2011). In contrast, we observed little or no effect of the CLA diet on the gene expression related to lipogenesis in AT at wk 15, different from the results reported by Harvatine et al. (2009). The discrepancy 
may have resulted from the differences in CLA isomer type (mixture of cis-9,trans-11 and trans-10,cis-12 CLA in diet vs. pure trans-10, cis-12 CLA through abomasal infusion) and doses (10.0-15.0 g/d for each isomer vs. $7.5 \mathrm{~g} / \mathrm{d}$ trans-10,cis-12 CLA) between the present study and Harvatine et al. (2009), respectively.

Collectively, both the CLA and HSO treatments downregulated lipolysis in AT at gene expression level at early lactation when cows were in NEB, whereas the effects disappeared in mid lactation when EB returned to positive. In contrast, a potential upregulation of lipogenesis was observed only in the HSO group but not in the CLA group and only in mid versus early lactation. Therefore, the response of AT to MFD may be dependent on the energy status of the cows, the stage of lactation, or the composition of the diet causing MFD. These alterations of the lipid metabolism in AT reflected the shift of energy partitioning toward AT and might have increased body fat reserves during MFD.

\section{Insulin Signaling and Ceramide Metabolism During MFD}

Regardless of diet, the transcription of most candidate genes involved in insulin signaling, inflammatory response, and ceramide metabolism considerably increased over time, which can be considered as a part of the physiological adaptation to the transition from NEB to positive EB. Overall, the CLA diet induced smaller variation in the expression of insulin-related genes from wk 3 to 15 compared with the other 2 groups. We suggest that the metabolic challenges at early lactation may be attenuated by the CLA diet and this may lead to a milder physiological adaptation to the transition compared with the other 2 diets.

The CLA diet tended to alter the local inflammatory responses in AT by upregulating TLR 4 and NFKB1 expression. It can be interpreted that the activation of TLR 4 and its downstream gene NFKB1 potentially upregulated the inflammatory signaling that stimulated the production of proinflammatory cytokines (Shi et al., 2006; Kawai and Akira, 2007), which is in line with the findings in human and mouse, suggesting that the anti-adipogenic effect of trans-10,cis-12 CLA was associated with the upregulation of NFKB-induced inflammatory response (Chung et al., 2005; Hommelberg et al., 2010). The transcriptional upregulation of AT inflammation seemed to be contradictory to the change in systemic inflammation under CLA treatment. However, the influence of the CLA diet on systemic inflammation may have been derived from its effects on hepatic metabolism because the acute phase proteins used as inflammation indicators are mainly synthesized in the liver (Bertoni and Trevisi, 2013; Tothova et al., 2014), which may explain the different responses of between systemic inflammation and AT inflammation to the CLA diet. An alternative interpretation of TLR 4 and NFKB1 upregulation is that it indicated the resistance of AT to inflammatory stimuli as suggested by Chen et al. (2012) and Minuti et al. (2015), which was in line with our observation in systemic inflammation. In addition, the CLA diet may affect the PI3K insulin signaling pathway by altering the expression of AKT2. Pettersson et al. (2013) suggested the importance of AKT2 on insulin signaling as the mRNA abundance of AKT2 was inversely correlated with the index indicating IR. However, it cannot be exclusively concluded that IR was reduced in the CLA group only based on the upregulation of AKT2 because the expression of its upstream gene IRS1 in PI3K pathway was not affected by the CLA diet.

The cis-9,trans-11 and trans-10,cis-12 CLA were reported to have different influences on IR in human and mouse adipocytes. Feeding cis-9,trans-11 CLA to mice was found to improve whole-body insulin sensitivity, increase the level of insulin-signaling pathway proteins, and decrease the transcription of pro-inflammatory cytokines in white AT, including interleukin-6 and tumor necrosis factor $\alpha$ (Moloney et al., 2007). In contrast, trans-10, cis-12 CLA was reported to increase IR in human and mouse adipocytes by promoting the inflammatory responses (House et al., 2005). In the present study, we suggest that the CLA diet likely attenuated IR in AT of dairy cows based on the profiles of EB, BW, NEFA, BHB, and the transcription of genes involved in lipid metabolism. However, the current results are insufficient to indicate the dominant CLA isomer that influenced AT metabolism as the effect of different isomers in ruminants may be different from that known in monogastrics. In addition, the differences in energy status and CLA doses pose further difficulties in the comparison between studies on ruminants and those on human and rodents. In addition, the upregulation of proinflammatory genes in AT seemed to be contradictory to the attenuated IR we expected. However, Hommelberg et al. (2010) reported that trans-10, cis-12 CLA increased NFKB activation 13-fold without inducing IR in cultured murine skeletal muscle cells. Moreover, the IR in AT may be also associated with systemic inflammation, which was reduced by the CLA supplement.

The CLA diet may influence IR through the regulation of ceramide metabolism at gene expression level. The SPTLC1 and SPTLC2 encode the long-chain subunits of serine palmitoyltransferase, the rate-limiting enzyme involved in ceramide de novo synthesis (Hornemann et al., 2009; Gault et al., 2010). The higher SPTLC1 expression in the CLA group at wk 3 may 
indicate potentially greater ceramide synthesis compared with the other 2 groups. However, the hydrolysis of ceramide may be promoted by the CLA diet at the same time, deduced from the upregulation of $A S A H 1$, a gene encoding acid ceramidase (Gault et al., 2010). These changes jointly suggested that the CLA group may have more active ceramide metabolism compared with the CON and HSO groups. Previously, Wang and Fromm (2015) observed in 3T3-L1 adipocytes that trans-10,cis-12 CLA treatment largely elevated the levels of sphinganine and sphingosine, an intermediate in ceramide de novo synthesis and a product of ceramide hydrolysis, respectively, which corresponds to the upregulation of SPTLC1 and ASAH1 expression in our CLA group. In addition, they observed increased ceramide level in the cell culture treated by trans-10, cis-12 CLA and claimed the lipid-lowering effect of CLA to be ceramide-dependent. Similar elevation of ceramide level in the skeletal muscle and increased IR was reported in overweight and nondiabetic humans who received dietary supplement of cis-9,trans-11 and trans-10,cis-12 CLA (Thrush et al., 2007). However, the current results were insufficient to unambiguously conclude that ceramide homeostasis changed as no measurements were conducted on ceramide concentration.

Collectively, the CLA diet potentially promoted the inflammatory responses in AT and influenced the insulin signaling and ceramide metabolism pathways in AT of dairy cows at gene expression level mainly at early lactation. However, it cannot be concluded that the CLA diet suppressed the lipid mobilization from AT through the regulation of IR because a contradiction exists between the indications of IR based on the physiological measurements and the gene expression profiles associated with inflammation in AT. Alternatively, CLA may influence the lipid metabolism by directly suppressing PPAR $\gamma$ activity through the inhibition of endogenous ligand formation (Brown et al., 2003). In contrast to the CLA diet, the HSO diet had no influence on the transcription of insulin-related candidate genes at early lactation. At wk 15, the HSO group displayed potentially more active insulin signaling and greater ceramide production through sphingomyelin hydrolysis compared with the other 2 groups, as suggested by the higher expression of $A K T 2$ and SMPD1. However, the present study provided insufficient evidence to assess the effects of HSO diet on IR. Overall, the CLA and HSO diets induced different effects in the regulation of IR-associated pathways, although they resulted in similar effects in suppressing the lipid mobilization from AT. The difference between the diets may have partly resulted from their different energy contents. Moreover, dietary PUFA supplement is believed to induce MFD by modifying ruminal biohydrogenation of fatty acids. Shingfield et al. (2006) provided cows a similar oil supplement as in the present study and observed the changes in the concentration of various fatty acids in milk, including 4:0 to 18:0 (even number of carbon atoms), cis 18:1, trans $18: 1$, trans $18: 2$, trans9,trans-11 CLA, 20:5n-3, and 22:6n-3, in addition to the elevation of trans-10, cis-12 and cis-9,trans-11 CLA. On the other hand, increases in various trans-10 containing intermediates but no change in cis-9,trans-11 and trans-10,cis-12 CLA in the digesta flow at the omasum were observed in cows fed a high-concentrate diet supplemented with sunflower oil (Ventto et al., 2017). Therefore, the MFD induced by dietary PUFA may result from the comprehensive effects of various modified biohydrogenation intermediates rather than simply from that of specific CLA isomers.

\section{CONCLUSIONS}

The diet containing a mixture of trans-10,cis-12 CLA and cis-9,trans-11 CLA and the high-starch diet supplemented with a mixture of sunflower oil and fish oil (2:1) effectively depressed milk fat yield and content at early (wk 3) and mid lactation (wk 15) in the absence of significant changes in milk protein and lactose contents. In addition, the HSO diet considerably lowered DM and ME intakes from wk 3 to 15 . The decreased energy intake may result in the decrease in milk yield and milk fat yield in the HSO group from wk 3 to 15 . As a consequence of decreased nutrient requirement for milk synthesis, both the CLA and HSO diets potentially decreased the mobilization of body fat from subcutaneous AT as deduced from the reduced transcription of lipolytic genes in AT at early lactation when dairy cows were in NEB, and supported by the lower blood NEFA and BHB levels in these groups compared with the control at the same time point. The suppression on lipolysis in AT by these 2 diets diminished at mid lactation when EB returned to positive. The CLA and HSO diets displayed no effect on the lipogenesis in AT at early lactation. However, increased lipogenesis at gene expression level was observed in AT of the HSO group at mid lactation. Collectively, the CLA and HSO diets induced a shift in energy partitioning from mammary gland toward AT. The effects were particularly obvious during the severe NEB at early lactation. The CLA and HSO diets may regulate the lipid metabolism in AT through different mechanisms because the CLA diet affected the expression of genes involved in insulin signaling pathways, inflammatory responses, and ceramide metabolism, whereas little change in these pathways was observed in cows receiving the HSO diet. 


\section{ACKNOWLEDGMENTS}

The experiment was designed by the late Kevin Shingfield, and his scientific expertise and inspiration were of utmost importance throughout the study. The financial support, and provision of CLA supplement and fish oil by BASF, Ludwigshafen, Germany, is appreciated. The gene expression analyses were funded by Niemi-säätiö, Finland, and Future Fund of the University of Helsinki. NQ was financially supported by the AGFOREE Doctoral Programme in Sustainable Use of Renewable Natural Resources at the University of Helsinki.

\section{REFERENCES}

Adewuyi, A. A., E. Gruys, and F. J. C. M. van Eerdenburg. 2005 Non esterified fatty acids (NEFA) in dairy cattle. A review. Vet. Q. 27:117-126.

Ahnadi, C. E., N. Beswick, L. Delbecchi, J. J. Kennelly, and P. Lacasse. 2002. Addition of fish oil to diets for dairy cows. II. Effects on milk fat and gene expression of mammary lipogenic enzymes. J. Dairy Res. 69:521-531.

Andersen, C., J. Jensen, and T. Orntoft. 2004. Normalization of realtime quantitative reverse transcription-PCR data: A model-based variance estimation approach to identify genes suited for normalization, applied to bladder and colon cancer data sets. Cancer Res. 64:5245-5250.

Angulo, J., L. Mahecha, K. Nuernberg, G. Nuernberg, D. Dannenberger, M. Olivera, M. Boutinaud, C. Leroux, E. Albrecht, and L. Bernard. 2012. Effects of polyunsaturated fatty acids from plant oils and algae on milk fat yield and composition are associated with mammary lipogenic and SREBF1 gene expression. Animal 6:1961-1972

Ballou, M. A., R. C. Gomes, S. O. Juchem, and E. J. DePeters. 2009. Effects of dietary supplemental fish oil during the peripartum period on blood metabolites and hepatic fatty acid compositions and total triacylglycerol concentrations of multiparous Holstein cows. J. Dairy Sci. 92:657-669.

Bauman, D. E., and J. M. Griinari. 2003. Nutritional regulation of milk fat synthesis. Annu. Rev. Nutr. 23:203-227.

Bauman, D. E., K. J. Harvatine, and A. L. Lock. 2011. Nutrigenomics, rumen-derived bioactive fatty acids, and the regulation of milk fat synthesis. Annu. Rev. Nutr. 31:299-319.

Baumgard, L., B. Corl, D. Dwyer, A. Saebo, and D. Bauman. 2000. Identification of the conjugated linoleic acid isomer that inhibits milk fat synthesis. Am. J. Physiol. Regul. Integr. Comp. Physiol. 278:R179-R184.

Bell, A. 1995. Regulation of organic nutrient metabolism during transition from late pregnancy to early lactation. J. Anim. Sci. 73:2804-2819.

Bernard, L., P. Toral, J. Rouel, and Y. Chilliard. 2016. Effects of extruded linseed and level and type of starchy concentrate in a diet containing fish oil on dairy goat performance and milk fatty acid composition. Anim. Feed Sci. Technol. 222:31-42.

Bertoni, G., and E. Trevisi. 2013. Use of the liver activity index and other metabolic variables in the assessment of metabolic health in dairy herds. Vet. Clin. North Am. Food Anim. Pract. 29:413-431.

Block, S., W. Butler, R. Ehrhardt, A. Bell, M. Van Amburgh, and Y. Boisclair. 2001. Decreased concentration of plasma leptin in periparturient dairy cows is caused by negative energy balance. J. Endocrinol. 171:339-348.

Brown, J. M., M. S. Boysen, S. S. Jensen, R. F. Morrison, J. Storkson, R. Lea-Currie, M. Pariza, S. Mandrup, and M. K. McIntosh. 2003. Isomer-specific regulation of metabolism and PPARgamma signaling by CLA in human preadipocytes. J. Lipid Res. 44:1287-1300.
Calamari, L., A. Ferrari, A. Minuti, and E. Trevisi. 2016. Assessment of the main plasma parameters included in a metabolic profile of dairy cow based on Fourier transform mid-infrared spectroscopy: Preliminary results. BMC Vet. Res. 12:4.

Chavez, J. A., T. A. Knotts, L. Wang, G. Li, R. T. Dobrowsky, G. L. Florant, and S. A. Summers. 2003. A role for ceramide, but not diacylglycerol, in the antagonism of insulin signal transduction by saturated fatty acids. J. Biol. Chem. 278:10297-10303.

Chavez, J. A., and S. A. Summers. 2012. A ceramide-centric view of insulin resistance. Cell Metab. 15:585-594.

Chen, Y., M. Oba, and L. L. Guan. 2012. Variation of bacterial communities and expression of toll-like receptor genes in the rumen of steers differing in susceptibility to subacute ruminal acidosis. Vet. Microbiol. 159:451-459.

Chung, S. K., J. M. Brown, J. N. Provo, R. Hopkins, and M. K. McIntosh. 2005. Conjugated linoleic acid promotes human adipocyte insulin resistance through NF kappa B-dependent cytokine production. J. Biol. Chem. 280:38445-38456.

Dirandeh, E., A. Towhidi, Z. Ansari, S. Zeinoaldini, and M. Ganjkhanlou. 2016. Effects of dietary supplementation with different polyunsaturated fatty acids on expression of genes related to somatotropic axis function in the liver, selected blood indicators, milk yield and milk fatty acids profile in dairy cows. Ann. Anim. Sci. 16:1045-1058.

do Prado, R. M., C. Cortes, C. Benchaar, and H. V. Petit. 2015. Interaction of sunflower oil with monensin on milk composition, milk fatty acid profile, digestion, and ruminal fermentation in dairy cows. Anim. Feed Sci. Technol. 207:85-92.

Drackley, J., H. Dann, G. Douglas, N. Guretzky, N. Litherland, J. Underwood, and J. Loor. 2005. Physiological and pathological adaptations in dairy cows that may increase susceptibility to periparturient diseases and disorders. Ital. J. Anim. Sci. 4:323-344.

European Council. 1986. Council Directive of 24 November 1986 on the approximation of laws, regulations and administrative provisions of the Member States regarding the protection of animals used for experimental and other scientific purposes (86/609/EEC). Off. J. Eur. Comm. L358:1-28.

Furuhashi, M., and G. S. Hotamisligil. 2008. Fatty acid-binding proteins: Role in metabolic diseases and potential as drug targets. Nat. Rev. Drug Discov. 7:489-503.

Galamb, E., V. Faigl, M. Keresztes, Z. Csillik, A. Troescher, P. Elek, M. Kulcsar, G. Huszenicza, H. Febel, and F. Husveth. 2017. Effect of pre- and post-partum supplementation with lipid-encapsulated conjugated linoleic acid on milk yield and metabolic status in multiparous high-producing dairy cows. J. Anim. Physiol. Anim. Nutr. (Berl.) 101:1026-1035.

Gault, C. R., L. M. Obeid, and Y. A. Hannun. 2010. An overview of sphingolipid metabolism: From synthesis to breakdown. Adv. Exp. Med. Biol. 688:1-23.

Gervais, R., J. W. McFadden, A. J. Lengi, B. A. Corl, and P. Y. Chouinard. 2009. Effects of intravenous infusion of trans-10, cis-12 18: 2 on mammary lipid metabolism in lactating dairy cows. J. Dairy Sci. 92:5167-5177.

Grummer, R., and D. Carroll. 1991. Effects of dietary-fat on metabolic disorders and reproductive-performance of dairy-cattle. J. Anim. Sci. 69:3838-3852

Harvatine, K. J., and D. E. Bauman. 2006. SREBP1 and thyroid hormone responsive spot 14 (S14) are involved in the regulation of bovine mammary lipid synthesis during diet-induced milk fat depression and treatment with CLA. J. Nutr. 136:2468-2474.

Harvatine, K. J., J. W. I. I. Perfield, and D. E. Bauman. 2009. Expression of enzymes and key regulators of lipid synthesis is upregulated in adipose tissue during CLA-induced milk fat depression in dairy cows. J. Nutr. 139:849-854.

Hötger, K., H. M. Hammon, C. Weber, S. Goers, A. Troescher, R. M. Bruckmaier, and C. C. Metges. 2013. Supplementation of conjugated linoleic acid in dairy cows reduces endogenous glucose production during early lactation. J. Dairy Sci. 96:2258-2270.

Hommelberg, P. P. H., R. C. J. Langen, A. M. W. J. Schols, A. L. M. Van Essen, F. J. M. Snepvangers, R. P. Mensink, and J. Plat. 2010. Trans fatty acid-induced NF- $\kappa$ B activation does not induce 
insulin resistance in cultured murine skeletal muscle cells. Lipids $45: 285-290$.

Hornemann, T., A. Penno, M. F. Ruetti, D. Ernst, F. Kivrak-Pfiffner, L. Rohrer, and A. von Eckardstein. 2009. The SPTLC3 subunit of serine palmitoyltransferase generates short chain sphingoid bases. J. Biol. Chem. 284:26322-26330.

House, R. L., J. P. Cassady, E. J. Eisen, M. K. McIntosh, and J. Odle. 2005. Conjugated linoleic acid evokes de-lipidation through the regulation of genes controlling lipid metabolism in adipose and liver tissue. Obes. Rev. 6:247-258.

Hutchinson, I., M. J. de Veth, C. Stanton, R. J. Dewhurst, P. Lonergan, A. C. O. Evans, and S. T. Butler. 2011. Effects of lipidencapsulated conjugated linoleic acid supplementation on milk production, bioenergetic status and indicators of reproductive performance in lactating dairy cows. J. Dairy Res. 78:308-317.

Ingvartsen, K. L. 2006. Feeding- and management-related diseases in the transition cow-Physiological adaptations around calving and strategies to reduce feeding-related diseases. Anim. Feed Sci. Technol. 126:175-213.

Invernizzi, G., S. Modina, D. Corbani, V. Bronzo, L. F. Pisani, J. M. Caputo, A. Agazzi, V. Dell'Orto, and G. Savoini. 2016. Hepatic and subcutaneous adipose tissue variations in transition dairy goats fed saturated or unsaturated fat supplemented diets. Small Rumin. Res. 144:211-219.

Kalscheur, K. F., B. B. Teter, L. S. Piperova, and R. A. Erdman. 1997. Effect of dietary forage concentration and buffer addition on duodenal flow of trans-C-18:1 fatty acids and milk fat production in dairy cows. J. Dairy Sci. 80:2104-2114.

Kawai, T., and S. Akira. 2007. Signaling to NF-кB by toll-like receptors. Trends Mol. Med. 13:460-469.

Kennedy, A., A. Overman, K. LaPoint, R. Hopkins, T. West, C Chuang, K. Martinez, D. Bell, and M. McIntosh. 2009. Conjugated linoleic acid-mediated inflammation and insulin resistance in human adipocytes are attenuated by resveratrol. J. Lipid Res. 50:225-232.

Knapp, J. R., H. C. Freetly, B. L. Reis, C. C. Calvert, and R. L. Baldwin. 1992. Effects of somatotropin and substrates on patterns of liver metabolism in lactating dairy cattle. J. Dairy Sci. 75:1025-1035.

Kokkonen, T., J. Taponen, T. Anttila, L. Syrjala-Qvist, C. Delavaud, Y. Chilliard, M. Tuori, and A. Tesfa. 2005. Effect of body fatness and glucogenic supplement on lipid and protein mobilization and plasma leptin in dairy cows. J. Dairy Sci. 88:1127-1141.

LeBlanc, S. 2010. Monitoring metabolic health of dairy cattle in the transition period. J. Reprod. Dev. 56:S29-S35.

Minuti, A., A. Palladino, M. J. Khan, S. Alqarni, A. Agrawal, F. Piccioli-Capelli, F. Hidalgo, F. C. Cardoso, E. Trevisi, and J. J. Loor. 2015. Abundance of ruminal bacteria, epithelial gene expression, and systemic biomarkers of metabolism and inflammation are altered during the peripartal period in dairy cows. J. Dairy Sci. 98:8940-8951.

Moloney, F., S. Toomey, E. Noone, A. Nugent, B. Allan, C. E. Loscher, and H. M. Roche. 2007. Antidiabetic effects of cis-9, trans-11-conjugated linoleic acid may be mediated via anti-inflammatory effects in white adipose tissue. Diabetes 56:574-582.

Moore, C., H. Hafliger, O. Mendivil, S. Sanders, D. Bauman, and L. Baumgard. 2004. Increasing amounts of conjugated linoleic acid (CLA) progressively reduces milk fat synthesis immediately postpartum. J. Dairy Sci. 87:1886-1895.

Natural Resources Institute Finland. 2015. Energy Requirements for Dairy Cows. Accessed Jun. 13, 2015. http://www.luke.fi/ rehutaulukot.

Odens, L. J., R. Burgos, M. Innocenti, M. J. VanBaale, and L. H. Baumgard. 2007. Effects of varying doses of supplemental conjugated linoleic acid on production and energetic variables during the transition period. J. Dairy Sci. 90:293-305.

Perfield, J., G. Bernal-Santos, T. Overton, and D. Bauman. 2002. Effects of dietary supplementation of rumen-protected conjugated linoleic acid in dairy cows during established lactation. J. Dairy Sci. 85:2609-2617.
Pettersson, A. M. L., B. M. Stenson, S. Lorente-Cebrian, D. P. Andersson, N. Mejhert, J. Kratzel, G. Astrom, I. Dahlman, A. V. Chibalin, P. Arner, and J. Laurencikiene. 2013. LXR is a negative regulator of glucose uptake in human adipocytes. Diabetologia 56:2044-2054.

Piccioli-Cappelli, F., J. J. Loor, C. J. Seal, A. Minuti, and E. Trevisi. 2014. Effect of dietary starch level and high rumen-undegradable protein on endocrine-metabolic status, milk yield, and milk composition in dairy cows during early and late lactation. J. Dairy Sci. 97:7788-7803.

Pirondini, M., S. Colombini, M. Mele, L. Malagutti, L. Rapetti, G. Galassi, and G. M. Crovetto. 2015. Effect of dietary starch concentration and fish oil supplementation on milk yield and composition, diet digestibility, and methane emissions in lactating dairy cows. J. Dairy Sci. 98:357-372.

Pupovac, V., and M. Petrovecki. 2011. Summarizing and presenting numerical data. Biochem. Med. (Zagreb) 21:106-110.

Qin, N., T. Kokkonen, S. Salin, T. Seppanen-Laakso, J. Taponen, A. Vanhatalo, and K. Elo. 2017. Prepartal overfeeding alters the lipidomic profiles in the liver and the adipose tissue of transition dairy cows. Metabolomics 13:21.

Rico, J. E., V. V. R. Bandaru, J. M. Dorskind, N. J. Haughey, and J. W. McFadden. 2015. Plasma ceramides are elevated in overweight Holstein dairy cows experiencing greater lipolysis and insulin resistance during the transition from late pregnancy to early lactation. J. Dairy Sci. 98:7757-7770.

Rico, J. E., S. S. Samii, A. T. Mathews, J. Lovett, N. J. Haughey, and J. W. McFadden. 2017. Temporal changes in sphingolipids and systemic insulin sensitivity during the transition from gestation to lactation. PLoS One 12:e0176787.

Rozen, S., and H. Skaletsky. 2000. Primer3 on the WWW for General Users and for Biologist Programmers. Pages 365-386 in Bioinformatics Methods and Protocols. Methods in Molecular Biol$\mathrm{ogy}^{\mathrm{TM}}$. Vol. 132. S. Misener and S. A. Krawetz, ed. Humana Press, Totowa, NJ.

Ruijter, J. M., C. Ramakers, W. M. Hoogaars, Y. Karlen, O. Bakker, M. J. van den Hoff, and A. F. Moorman. 2009. Amplification efficiency: Linking baseline and bias in the analysis of quantitative PCR data. Nucleic Acids Res. 37:e45.

Salin, S., J. Taponen, K. Elo, I. Simpura, A. Vanhatalo, R. Boston, and T. Kokkonen. 2012. Effects of abomasal infusion of tallow or camelina oil on responses to glucose and insulin in dairy cows during late pregnancy. J. Dairy Sci. 95:3812-3825.

Saremi, B., S. Winand, P. Friedrichs, A. Kinoshita, J. Rehage, S. Daenicke, S. Haeussler, G. Breves, M. Mielenz, and H. Sauerwein. 2014. Longitudinal profiling of the tissue-specific expression of genes related with insulin sensitivity in dairy cows during lactation focusing on different fat depots. PLoS One 9:e86211.

Schlegel, G., R. Ringseis, W. Windisch, F. J. Schwarz, and K. Eder. 2012. Effects of a rumen-protected mixture of conjugated linoleic acids on hepatic expression of genes involved in lipid metabolism in dairy cows. J. Dairy Sci. 95:3905-3918.

Schmitt, E., M. A. Ballou, M. N. Correa, E. J. DePeters, J. K. Drackley, and J. J. Loor. 2011. Dietary lipid during the transition period to manipulate subcutaneous adipose tissue peroxisome proliferator-activated receptor-gamma co-regulator and target gene expression. J. Dairy Sci. 94:5913-5925.

Selim, S., T. Kokkonen, J. Taponen, A. Vanhatalo, and K. Elo. 2015. Effect of prepartal ad libitum feeding of grass silage on transcriptional adaptations of the liver and subcutaneous adipose tissue in dairy cows during the periparturient period. J. Dairy Sci. 98:55155528 .

Selim, S., S. Salin, J. Taponen, A. Vanhatalo, T. Kokkonen, and K. T. Elo. 2014. Prepartal dietary energy alters transcriptional adaptations of the liver and subcutaneous adipose tissue of dairy cows during the transition period. Physiol. Genomics 46:328-337.

Shi, H., M. V. Kokoeva, K. Inouye, I. Tzameli, H. Yin, and J. S. Flier. 2006. TLR4 links innate immunity and fatty acid-induced insulin resistance. J. Clin. Invest. 116:3015-3025. 
Shingfield, K. J., D. E. Beever, C. K. Reynolds, S. K. Gulati, D. J. Humphries, B. Lupoli, G. Hervas, and M. J. Griinari. 2004. Effect of rumen protected conjugated linoleic acid on energy metabolism of dairy cows during early to mid-lactation. J. Anim. Sci. 82:307-307.

Shingfield, K. J., L. Bernard, C. Leroux, and Y. Chilliard. 2010. Role of trans fatty acids in the nutritional regulation of mammary lipogenesis in ruminants. Animal 4:1140-1166.

Shingfield, K. J., S. Jaakkola, and P. Huhtanen. 2002. Effect of forage conservation method, concentrate level and propylene glycol on diet digestibility, rumen fermentation, blood metabolite concentrations and nutrient utilisation of dairy cows. Anim. Feed Sci. Technol. 97:1-21.

Shingfield, K. J., C. Reynolds, G. Hervas, J. Griinari, A. Grandison, and D. Beever. 2006. Examination of the persistency of milk fatty acid composition responses to fish oil and sunflower oil in the diet of dairy cows. J. Dairy Sci. 89:714-732.

Thering, B. J., D. E. Graugnard, P. Piantoni, and J. J. Loor. 2009 Adipose tissue lipogenic gene networks due to lipid feeding and milk fat depression in lactating cows. J. Dairy Sci. 92:4290-4300.

Thrush, A. B., A. Chabowski, G. J. Heigenhauser, B. W. McBride, M. Or-Rashid, and D. J. Dyck. 2007. Conjugated linoleic acid increases skeletal muscle ceramide content and decreases insulin sensitivity in overweight, non-diabetic humans. Appl. Physiol. Nutr. Metab. 32:372-382.

Tothova, C., O. Nagy, and G. Kovac. 2014. Acute phase proteins and their use in the diagnosis of diseases in ruminants: A review. Vet. Med. 59:163-180.

Trevisi, E., M. Amadori, S. Cogrossi, E. Razzuoli, and G. Bertoni. 2012. Metabolic stress and inflammatory response in high-yielding, periparturient dairy cows. Res. Vet. Sci. 93:695-704.

Trevisi, E., A. Ferrari, F. Piccioli-Cappelli, and G. Bertoni. 2008. Energy balance indexes and blood changes of dairy cows supple- mented with rumen protected CLA in late pregnancy and early lactation. J. Dairy Sci. 91(E-Suppl. 1):77. (Abstr.)

Urrutia, N., and K. J. Harvatine. 2017. Effect of conjugated linoleic acid and acetate on milk fat synthesis and adipose lipogenesis in lactating dairy cows. J. Dairy Sci. 100:5792-5804.

Vahmani, P., K. E. Glover, and A. H. Fredeen. 2014. Effects of pasture versus confinement and marine oil supplementation on the expression of genes involved in lipid metabolism in mammary, liver, and adipose tissues of lactating dairy cows. J. Dairy Sci. 97:4174-4183.

Vailati-Riboni, M., M. Kanwal, O. Bulgari, S. Meier, N. V. Priest, C. R. Burke, J. K. Kay, S. McDougall, M. D. Mitchell, C. G. Walker, M. Crookenden, A. Heiser, J. R. Roche, and J. J. Loor. 2016. Body condition score and plane of nutrition prepartum affect adipose tissue transcriptome regulators of metabolism and inflammation in grazing dairy cows during the transition period. J. Dairy Sci. 99:758-770.

Ventto, L., H. Leskinen, P. Kairenius, T. Stefanski, A. R. Bayat, J. Vilkki, and K. J. Shingfield. 2017. Diet-induced milk fat depression is associated with alterations in ruminal biohydrogenation pathways and formation of novel fatty acid intermediates in lactating cows. Br. J. Nutr. 117:364-376.

von Soosten, D., U. Meyer, M. Piechotta, G. Flachowsky, and S. Daenicke. 2012. Effect of conjugated linoleic acid supplementation on body composition, body fat mobilization, protein accretion, and energy utilization in early lactation dairy cows. J. Dairy Sci. 95:1222-1239

Wang, W., and M. Fromm. 2015. Sphingolipids are required for efficient triacylglycerol loss in conjugated linoleic acid treated adipocytes. PLoS One 10:e0119005.

Zened, A., A. Troegeler-Meynadier, T. Najar, and F. Enjalbert. 2012. Effects of oil and natural or synthetic vitamin $\mathrm{E}$ on ruminal and milk fatty acid profiles in cows receiving a high-starch diet. J. Dairy Sci. 95:5916-5926. 